J. Fixed Point Theory Appl. 19 (2017) 1

DOI 10.1007/s11784-017-0408-2

(C) Springer International Publishing 2017

Journal of Fixed Point Theory

and Applications

This special issue is dedicated to

\title{
Paul Rabinowitz
}

honouring a wide variety of great achievements

in analysis, topology and dynamics.

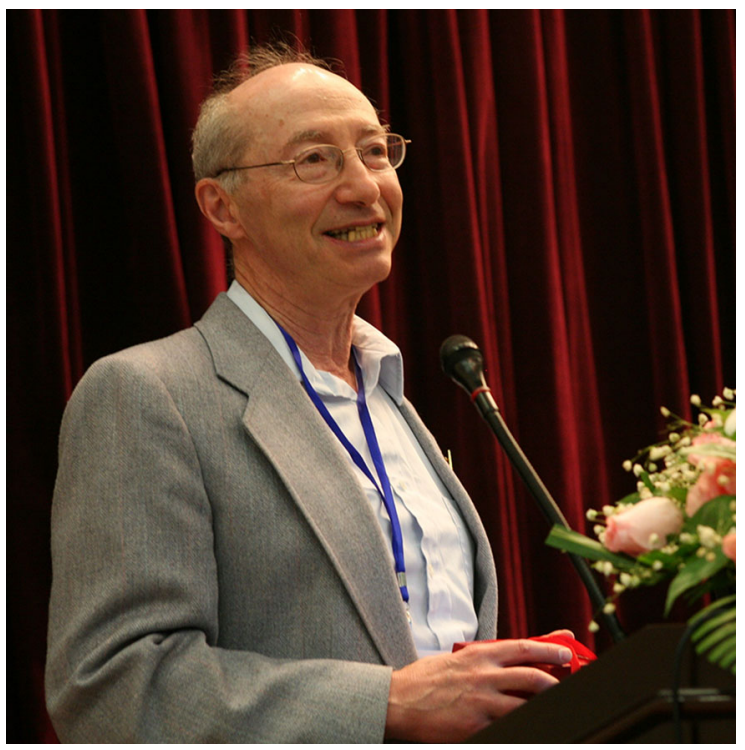

The Journal of Fixed Point Theory and Applications is grateful to Prof. Patricio Felmer and Prof. Yiming Long for their precious work as special editors of this special issue, and to the staff who assisted them, Ms Gladys Cavallone (Universidad de Chile in Santiago) and Ms Hongqin Li (Nankai University in Tianjin). 